\title{
The Acquiring Process of Entrepreneurship Competencies in Realist Airbrush Art
}

\author{
Bayu Rahmat Setiadi ${ }^{1, *}$, Suparmin $^{2}$, Slamet Priyanto $^{2}$, Henny Pratiwi $^{1}$, Sugiyono $^{1}$ \\ ${ }^{1}$ Department of Mechanical Engineering Education, Universitas Negeri Yogyakarta, Yogyakarta, Indonesia \\ ${ }^{2}$ Department of Mechanical Engineering Education, Universitas Sarjanawiyata Tamansiswa, Yogyakarta, Indonesia
}

\begin{tabular}{l} 
A R T I C L E I N F O \\
\hline Article history: \\
Received: 14 October, 2019 \\
Accepted: 05 February, 2020 \\
Online: 09 March, 2020 \\
\hline Keywords: \\
Realist Airbrush \\
Art and Technologies \\
Acquiring Process \\
Vocational High School \\
\hline
\end{tabular}

\begin{abstract}
A B S T R A C T
One of the creative industries with rapid growth is the airbrush industry. Airbrush art, especially realist, is identical to the field of automotive engineering in the combination of art and technology. The research is directed to prove how the difficult realist airbrush competency can be achieved by Vocational High School (VHS) students in a short time. Also, the research synchronises the increase in entrepreneurial understanding of VHS students in real business incubation in the realist airbrush industry. The final results show that entrepreneurial learning needs to add elements of art as a stage in the acquisition of real competencies.
\end{abstract}

\section{Introduction}

The creative industry is one of the creative economies that can stimulate the economy in Indonesia. Some of these creative sectors have great opportunities in solving the problem of unemployment in Indonesia [1]. Creative industries support almost half of Indonesia's foreign exchange [2]. Data shows that the number of entrepreneurs from the creative industries is $49 \%$ spread widely in some province in Indonesia where Yogyakarta Province as the centre [3].

Creative industries that grow in Indonesia have several subsectors include animation, architecture, design, photography, music, crafts, culinary, fashion, research and development, publishing, film, advertising, interactive games, performance art, visual arts, information technology, television, radio, and video. Some of these sectors, six sub-sectors with the highest growth, are television, film-animation-video, performing arts, crafts, and visual communication design [4]. One of the most desirable subsectors is craft and art [5]. Yogyakarta City is one of the contributors to the arts and crafts business in regional, national, and international export marketing [6].

The growth of the creative arts industry in Yogyakarta is a reflection of artists in Indonesia as inspiration for ideas and creativity. One of the trendy creative endeavours in this city is airbrush art. The famous airbrush in this city is Planet Airbrush Potlot. Potlot has been established since 2000 and has produced

\footnotetext{
*Bayu Rahmat Setiadi, Email: bayursetiadi@uny.ac.id
}

hundreds of airbrush works on automotive, painting, wall, and other media. Potlot won various international events. According to an art perspective, the realist airbrush technique is very complicated and is in great demand by many people because of the high level of detail and animate the character of the artwork [7]. So, Yogyakarta could be said as a place for artists in exploring art [8].

The effort to open a realist airbrush, as exemplified in the previous paragraph, explains that there are good prospects for Vocational High Schools (VHS) to produce graduates as airbrush entrepreneurs [9]. The trend of shifting from VHS graduates to entrepreneurs is due to the limited number of jobs for VHS graduates to get a new job. However, leading graduates to create airbrush art is an option to reduce the unemployment level of VHS graduates.

Based on the previous description, the researcher wants to examine how VHS students who are doing internships in the realist airbrush industry can be skilled in simple airbrushing. Besides, observing the process of acquiring entrepreneurial competencies about the business is the key to this paper because the research is unique and can be an inspiration for business people to be interested in opening up new business fields.

\section{Combining Art in Automotive for New Business Incubation} 2.1. Collaboration between creative industry subsector in
Indonesia 
The creative industry in Indonesia has a variety of sub-sectors. The Creative Economy Agency or abbreviation of Bekraf Indonesia has released 16 strategic sub-sectors, including animation, architecture, design, photography, music, crafts, culinary, etc. Some of these sub-sectors were developed in several iconic big cities such as Yogyakarta (handicraft city), Pekalongan (city of Batik), Bandung (fashion city) [10]. The iconic cities became a centre for business development and creative industries as well as references from various regions [11].

The collaboration between various industry sub-sectors is a good strategy in order to produce quality products. The products currently available are a combination of multidisciplinary or better known as Science, Technology, Engineering, Arts, and Mathematics (STEAM) [12]. Science and technology need to work together with art to manufacture products that are more accepted by society. It indicates that the creative industries sub-sectors need to collaborate dynamically and flexibly so that the products in the creative industries become more diverse and quality.

\subsection{Prospective realist airbrush as a promising business}

Fine art has two types, namely, pure and applied art [13]. Pure art, or better known as first works, is an expression of the soul that is etched through dots, lines, paintings, and other forms of images. Applied art is a form of application of artists to the media that it has designed. Airbrush, as an art-based painting technique, is an applied art that is expressively determined by painting in the media [14].

Realist airbrushes have advantages in producing real artwork. The examples are such as in murals, posters, contemporary, and painting [15]. Not many people are experts in painting realists in certain media. A high level of difficulty in drawing and depth in inspiration determines the success of a realist. Also, the airbrush technique requires much experience so that the results are more realistic and easily understood by connoisseurs of art [16]. Various challenges in airbrush art make the techniques needed in the business of painting and airbrush. Therefore, a realistic airbrush with complicated media such as vehicles, motorcycles, cars, trucks, and buses is an excellent business opportunity.

\subsection{VHS automotive students have potential in the realist} airbrush industry entrepreneurship

The curriculum determines VHS graduates to work, go to college, and be entrepreneurs [17]. The current curriculum design in Indonesia refers to the 2013 Curriculum. The contents of the curriculum with the priority of practicum indicate a change in mindset for VHS to increase psychomotor ability compared to cognitive and adaptive. For example, automotive skills in the curriculum spectrum in Indonesia limit the practice of basic painting. If this continues, the tendency of students to get late for the first job becomes a common problem in Indonesia. The entrepreneurship is like a medicine needed in solving the unemployment problem in Indonesia.

Policies in Indonesia encourage entrepreneurship in vocational education. Many studies have explored the opportunities for creative industry employment as a potential face of new entrepreneurs. Cheap, collaborative capital, a wide variety of products, and the dynamics of consumer change are ideal potentials in entrepreneurial learning. In the case of automotive engineering, the business of marketing and repair services are frequent, and consumers have regular customers who certainly reduce the interest of entrepreneurship for beginners.

\section{Research Method}

The study used a mixed-method with an explanatory cycle model. This method is in line with the process of acquiring competencies that have three observed research stages. The first step using phenomenology to reveal the process of achieving student competence in airbrush techniques. The next step is adopting experimentation in the form of pre-test and post-test to examine the first hypothesis. The last step is testing the second hypothesis with pre-test and post-test in order to validate the improvement of entrepreneurship skills in airbrush realism after the incubation process was carried out.

The population is 30 students at VHS Ma'arif-Salam, Magelang Regency, majoring in automotive engineering. Data collection techniques used were interviews and observations and questionnaires. Interviews were conducted to obtain in-depth information from the instructor. Meanwhile, the pre-test and posttest instruments will ask questions related to increasing understanding of both airbrush and entrepreneurship training data analysis by reducing the critical information based on coding and besides, interpreting the findings through a crosscheck of interviews and observations to the instructor. Descriptive statistics were used to measure the understanding of both airbrush and entrepreneurship training.

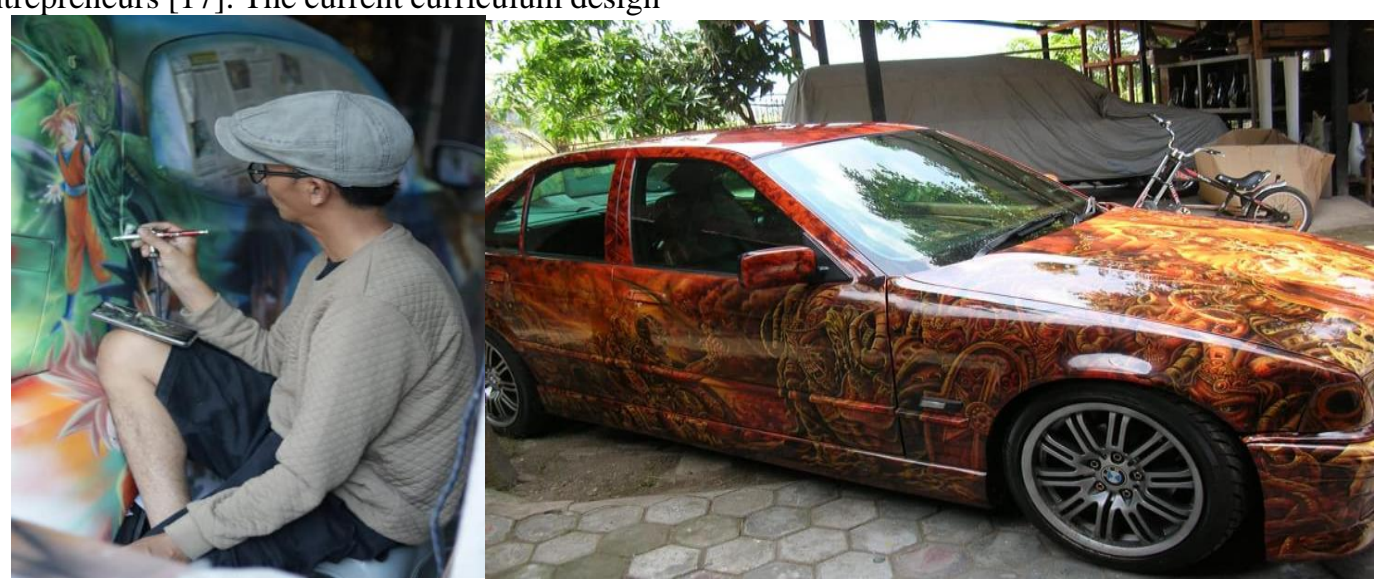

Figure 1: The Art of Collaborating with Automotive 


\section{Results}

The acquisition of entrepreneurial competence in the realist airbrush has two main scopes. They are achieving airbrush success and success in opening a business. The results of the two studies are mutually simultaneous to prepare VHS graduates to open the automotive business in the realist airbrush field. Based on observations, interviews, and data reduction, the flow chart as obtained for VHS students who were said to be amateur workers.
Figure 2 describes the process of obtaining entrepreneurial competence in airbrush skills. The process illustrates that the repetition of the process occurs as a stage of student learning. For example, students are often less thorough in sanding and caulking. The results of sandpaper and picking should be checked for smoothness because it has an impact on the final product. Therefore, the initial work raises many related cycles as capital to prepare an applicable and neat airbrush media. The improvement of airbrush realist skills is carried out continuously by conducting tests at the beginning and providing posttest after treatment.

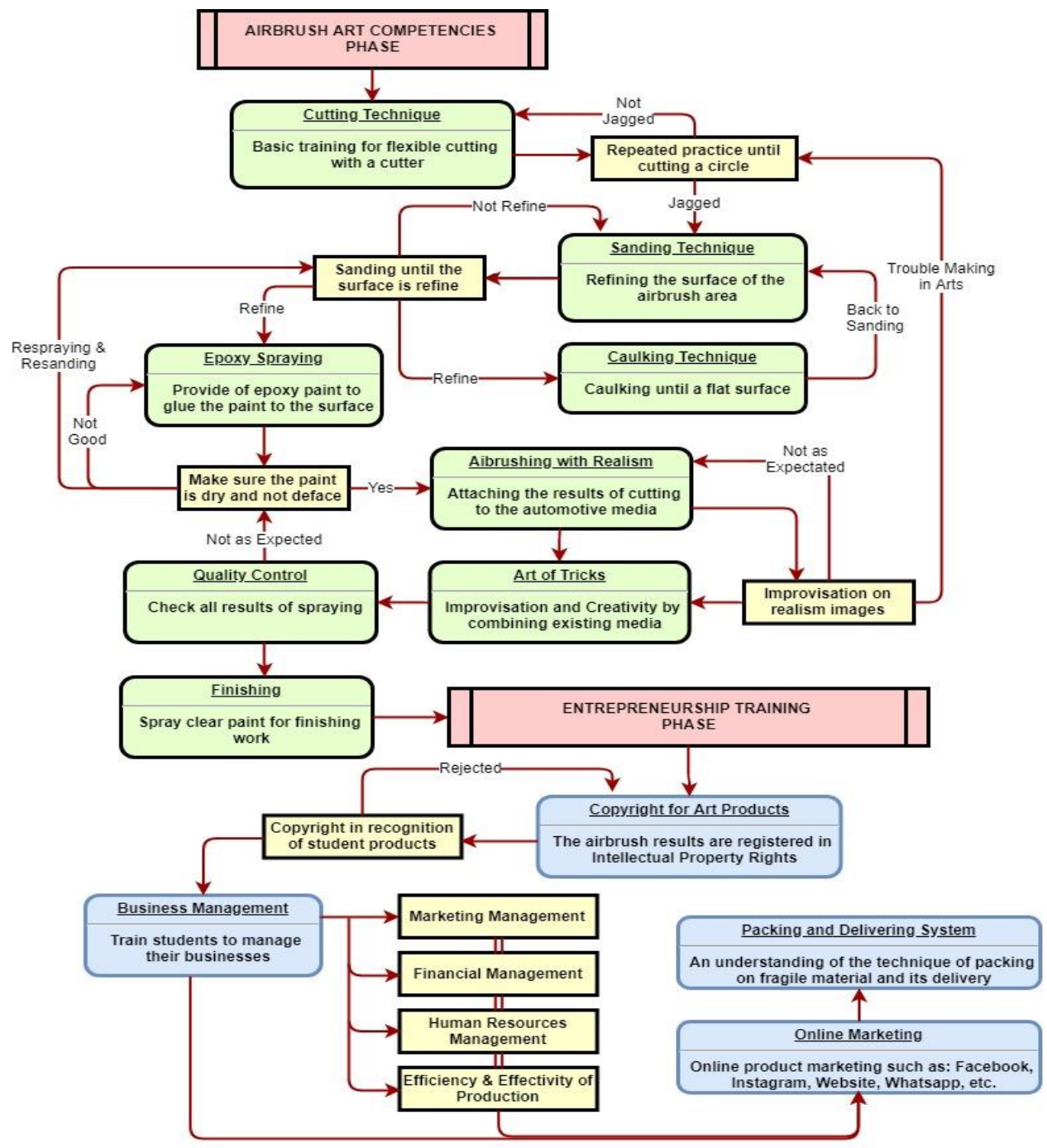

Figure 2: The Process of Forming Entrepreneurship Competence in the Automotive Realist Airbrush Business

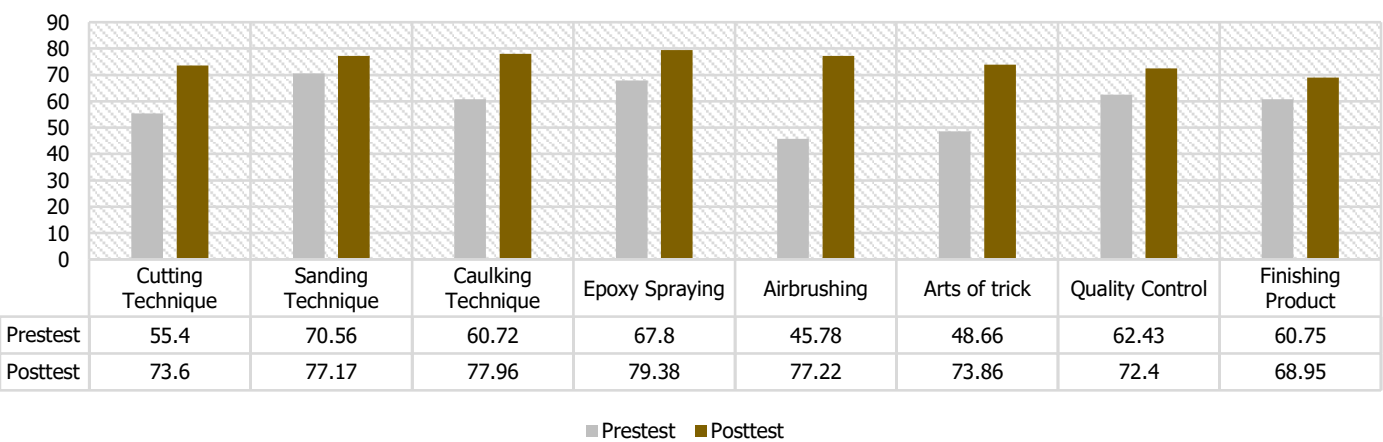

Figure 3: Realist Airbrush Skills in Pretest and Posttest 
There is a significant influence on students' skills due to airbrush training (Fig. 3). More than one-fifth of the posttest outperformed the pretest score, indicating that students' interest in painting was very high. Substantially, the enthusiasm of students to continue on the entrepreneurial step becomes an opportunity for them to be confident in opening a realist airbrush business. Positive responses to the creative industries in this sector need to be encouraged comprehensively.

The challenge in airbrush training based on interviews are cutting techniques, airbrushing, and arts of tricks. All three techniques require a lot of practice and material. These obstacles can be overcome if they often practice continuously to form these skills. Behaviorally, a child's skills will work well if he does repetitive work according to the object being worked on the workplace. Meanwhile, constructivism point of view states that learning can build independence in the field of arts, creation, and innovation.

The entrepreneurial skills of VHS students are measured by doing pretest and posttest before the airbrush training is carried out, and after they get the entrepreneurial knowledge. In the posttest, the skill of students increased by $11.38 \%$ compared to pretest. The following is a graph of the increasing entrepreneurial development of VHS students. The improvement of realist airbrush skills examination is carried out continuously by conducting tests at the beginning through a pretest and giving a posttest after treatment.

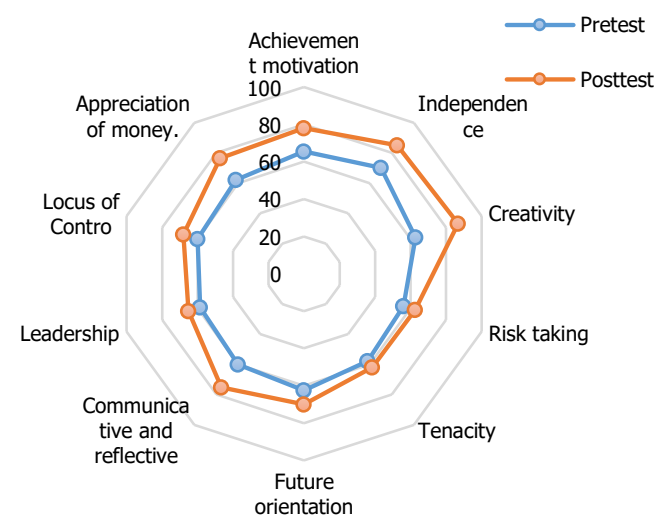

Figure 4. Distribution of VHS Student Entrepreneurship Experience Progress

The distribution of VHS student entrepreneurship experience progress diagram (Fig. 4) shows that there is an increase in all aspects of entrepreneurship criteria. The remarkable improvement is an increase in creativity, which is a quarter per cent of the value of the two tests. In the other side, there is a concern in the low level of tenacity. The short-term training and entrepreneurial experience have not significantly increased their tenacity level, but the entrepreneurship training after completing the product provides a significant increase in other criteria.

\section{Discussions}

Arts and automotive would be two beautiful fields of science if they integrated. Maeda proves that the existence of art in automotive design will increase the sale value of the vehicle [12]. A significant increase is very noticeable when automotive products begin to be marketed at certain specific events. The research findings show the acceleration of students' ability in the mastery of art in the automotive field on airbrush realism. The primary abilities of students become the first reason in increasing their motivation and interest to explore airbrush science based on the needs of automotive work.

Entrepreneurship that is in line with skills is an excellent opportunity to pursue the field of expertise [18]. Students with airbrush skills have a big challenge to open the airbrush business later after they graduate. This entrepreneurial theory will undoubtedly oppose the assumption of Prosser \& Quigley theory that working in the automotive field is required to work in the automotive industry [19]. This assumption began to shift since Dewey gave the freedom to determine the goals and lives of students following the needs and opportunities of students [20]. However, this finding is part of providing information to schools in Indonesia that VHS has great potential to direct graduates to become entrepreneurs.

\section{Conclusion}

There is a significant influence on students' skills due to airbrush training. More than $20 \%$ of the posttest outperformed the pretest score, indicating that students' interest in painting was very high. The distribution of VHS student entrepreneurship experience progress diagram also shows that there is an increase in all aspects of entrepreneurship criteria. The remarkable improvement is an increase in creativity which increase $25 \%$ after the training.

\section{Conflict of Interest}

The authors declare no conflict of interest.

\section{Acknowledgment}

Our thanks to the Directorate of Research and Community Service - Ministry of Research, Technology, and Higher Education of the Republic of Indonesia for funding research into the development of creative industries for VHS students. Researchers are grateful to all those who helped the research process.

\section{References}

[1] B. R. Setiadi and Suparmin, "Providing Space for Creative Industry SubSectors to Meet the Labor Market for Vocational School Graduates," in Advances in Social Science, Education and Humanities Research, 2017, vol. 102, no. Ictvt, pp. 309-313.

[2] M. E. Pangestu, Ekonomi Kreatif Indonesia 2025, no. 5. Jakarta: Departemen Perdagangan RI, 2015.

[3] Bekraf, Opus creative economy outlook 2019. Jakarta: Badan Ekonomi Kreatif, 2019.

[4] S. R. Maryunani and I. R. Mirzanti, "The Development of Entrepreneurship in Creative Industries with Reference to Bandung as a Creative City," Procedia - Soc. Behav. Sci., vol. 169, no. August 2014, pp. 387-394, 2015.

[5] ICCI, "KADIN Dorong Ekonomi Kreatif Yogyakarta," Indonesian Chamber of Commerce and Industry, 2017. .

[6] DIY Tourism Office, "Statistik Kepariwisataan 2015," Yogyakarta,Indonesia, 2015.

[7] X. Wang, "Realist painting and its relationship to my creative practice Realist painting and its relationship to my creative practice," Edith Cowan University, 2010.

[8] M. D. Marianto, "Surrealist Painting in Yogyakarta," University of Wollongong, 1995.

[9] B. R. Setiadi, Suparmin, S. Priyanto, and P. Roniwijaya, "Tracking the potential of vocational high school students leading to eighteen strategic 
creative industry sub-sectors in Indonesia," IOP Conf. Ser. Mater. Sci. Eng., vol. 535, no. 1, 2019.

[10] F. Z. Fahmi, S. Koster, and J. van Dijk, "The location of creative industries in a developing country: The case of Indonesia," Cities, vol. 59, pp. 66-79, 2016.

[11] M. B. Alexandri, E. Maulina, A. Chan, and R. W. S. Sumadinata, "Creative Industries: Existence of Arts Traditional Industries in Indonesia," Acad. Strateg. Manag. J., vol. 18, no. 1, pp. 1-12, 2019.

[12] J. Maeda, "STEM + Art = STEAM," STEAM, vol. 1, no. 1, pp. 1-3, 2013.

[13] C. P. Magill, "Pure and Applied Art: A Note on Johann Peter Hebel," 1957, pp. $183-188$.

[14] J. Lu, C. Barnes, S. DiVerdi, and A. Finkelstein, "RealBrush: Painting with examples of physical media," ACM Trans. Graph., vol. 32, no. 4, 2013.

[15] A. Oliver, "Critical realism in contemporary art," University of Pittsburgh, 2014.

[16] M. A. A. Soltan, "An Investigation into the History of the Airbrush and the Impact of the Conservation Treatment of Airbrushed Canvas Paintings Mohamed," University of Northumbria, 2015.

[17] H. Retnawati, S. Hadi, and A. C. Nugraha, "Vocational high school teachers' difficulties in implementing the assessment in curriculum 2013 in Yogyakarta Province of Indonesia,” Int. J. Instr., 2016.

[18] B. R. Setiadi, Suparmin, and Samidjo, "Preparing engineering students for entrepreneurial creative industries," Glob. J. Eng. Educ., vol. 20, no. 2, pp. 127-131, 2018.

[19] P. Sudira, "Indonesia vocational education praxis betwen," in Empowering Vocational Education and Training to Elevate National Economic Growth, 2014, pp. 190-200.

[20] J. Dewey, Democracy and Education. Hazleton: The Pennsylvania State University The, 2001. 